\title{
Clonal structure of Providencia alcalifaciens strains isolated from diarrhoeal stools in São Paulo, Brazil
}

\author{
BEATRIZ E. C. GUTH, KINUE IRINO* and LUIZ R. TRABULSI† \\ Department of Microbiology, Immunology and Parasitology, Universidade Federal de São Paulo - Escola \\ Paulista de Medicina, São Paulo, *Bacteriology Section, Instituto Adolfo Lutz, São Paulo and †Department of \\ Microbiology, Instituto de Ciências Biomédicas - Universidade de São Paulo, SP, Brazil
}

\begin{abstract}
Clonal analysis based on ribotyping demonstrated that Providencia alcalifaciens strains isolated mainly from diarrhoeal stools in São Paulo, Brazil, were clustered into two main groups. Eleven distinct ribotype patterns were identified with ClaI, EcoRV and MluI restriction endonucleases. $P$. alcalifaciens strains with invasive properties were of two ribotype patterns that differed from those identified among non-invasive strains. The ribotyping results confirmed that $P$. alcalifaciens strains associated with diarrhoeal disease in São Paulo represent distinct groups of strains. Although the invasive strains were isolated from different patients over an extended period they were clustered into two genetically related clones, which seemed to be distributed endemically in the population studied.
\end{abstract}

\section{Introduction}

Providencia alcalifaciens is a member of the Enterobacteriaceae and is thought to be a cause of diarrhoea [1]. Invasion has been proposed as the virulence mechanism of this organism [2] and this property was found commonly among $P$. alcalifaciens strains isolated in Bangladesh [3]. A previous study in São Paulo City, Brazil, [4] showed that although invasive $P$. alcalifaciens strains were encountered frequently, this virulence characteristic, in contrast with the data obtained in Bangladesh [3], did not predominate among isolates from patients with diarrhoea. These results led to the supposition that $P$. alcalifaciens strains associated with diarrhoea in São Paulo may comprise a diverse group of strains.

Several methods have been used to study genetic diversity among bacterial species. Analysis of DNA polymorphism in the chromosomal region containing the highly conserved rRNA genes, and referred to as ribotyping, was initially proposed as a general method for molecular identification of bacteria [5]. Since then, ribotyping has emerged as an important taxonomic tool, providing precise information about bacterial intra- and inter-species differentiation [6-8].

Received 1 April 1998; revised version accepted 19 June 1998.

Corresponding author: Dr B. E. C. Guth (e-mail: becguth.dmip @epm.br).
The purpose of this study was to analyse by ribotyping the genetic relationship of $P$. alcalifaciens strains described previously in association with diarrhoeal disease in São Paulo, Brazil.

\section{Materials and methods}

Bacterial strains

A total of $19 P$. alcalifaciens strains was studied. Most of the strains were isolated as pure cultures or from stool cultures in which no other bacterial enteropathogen was identified. Nine strains were invasive; the other strains did not show this characteristic. Except for two strains isolated from asymptomatic patients all the other strains were from diarrhoeal stools [4]. Invasion assays of HeLa cells were performed as described previously [4]. The characterisitics of the strains are presented in Table 1.

\section{Ribotyping}

The extraction of genomic DNA was performed according to Brenner et al. [9]. Initially, the DNA $(2 \mu \mathrm{g})$ of one of the strains (9938) was incubated with 18 restriction endonucleases (SmaI, Bam HI, SaII, HindIII, Xba I, PvuI, Kpn I, Hinfl, BglI, EcoRI, ClaI, $A v a \mathrm{I}, A c c \mathrm{I}, X h o \mathrm{I}, M l u \mathrm{I}, E c o \mathrm{RV}, B g l \mathrm{II}$ and $H a e \mathrm{II})$ ( $1 \mathrm{U} / \mu \mathrm{g}$ of DNA) according to the manufacturer's instructions (New England Biolabs) to select for the more appropriate endonucleases. Based on the number and distribution of fragments $C l a \mathrm{I}, E c o$ RV and $M l u \mathrm{I}$ 
restriction enzymes were selected for use. The DNA of all strains was then digested with these three enzymes, electrophoresed in agarose $0.8 \%$ gels and transferred to Hybond-N nylon membranes (Amersham International, San Jose, CA, USA) by Southern blotting [10]. The procedures for labelling the $16 \mathrm{~S}+23 \mathrm{~S}$ rRNA and the detection and hybridisation conditions were as described previously [6]. The cDNA probe was prepared by reverse transcription of $16 \mathrm{~S}+23 \mathrm{~S}$ rRNA from Escherichia coli with a DIG DNA labelling and detection kit (Boehringer Mannheim, Germany). Haemophilus aegyptius 3031 EcoRI DNA digest [11] was used as a size marker to estimate the fragment sizes of $P$. alcalifaciens DNA with a personal microcomputer and the DNA Star program. The genetic relationship and divergence between ribotypes were calculated from a genetic distance matrix, defined on the basis of similarity between the distinct fingerprints and represented in a dendrogram constructed with the NeighborJoining algorithm [12].

\section{Results and discussion}

In the present study ribotyping was used to genotypically characterise $P$. alcalifaciens strains associated with diarrhoea in São Paulo, Brazil.

Analysis of the $P$ alcalifaciens strains showed that different restriction endonuclease patterns were established after DNA digestion with ClaI, EcoRV and
$M l u \mathrm{I}$, electrophoresis and hybridising with the $E$. coli rRNA probe. rDNA profiles were considered distinct when there was a single band difference and were designated according to the restriction endonuclease used (C for Cla I, E for EcoRV and $\mathrm{M}$ for $M l u \mathrm{I}$ ). Side-by-side comparisons and precise size determinations were performed when similar patterns were observed among the strains studied. The ribotype patterns observed were reproducible, as several strains gave the same ribotype in different assays.

Nine Cla I rDNA profiles $(\mathrm{C} 1-\mathrm{C} 9)$ were identified, and they had eight or nine rDNA bands ranging from 2.5 to $17.6 \mathrm{~kb}$ (Fig. 1). Ten EcoRV (E1-E10) and eight Mlu I (M1-M8) profiles were observed. Representative patterns obtained with ClaI, EcoRV and $M l u \mathrm{I}$ are shown in Fig. 2. The ClaI and $M l u \mathrm{I}$ restriction patterns produced better discrimination of $P$. alcalifaciens strains than the EcoRV pattern, although EcoRV discriminated more patterns among strains belonging to the same ribotype as determined by Cla I (Table 1).

Ribotyping has been used widely for typing several bacterial pathogens, but its discriminatory ability varies from species to species. For Serratia marcescens strains it was more discriminating than biotyping [13] and for Yersinia enterocolitica it has been viewed as an alternative to bioserotyping [14]. However, it was not a reference method to discriminate between Salmonella strains [15]. Owen et al. [16] ribotyped

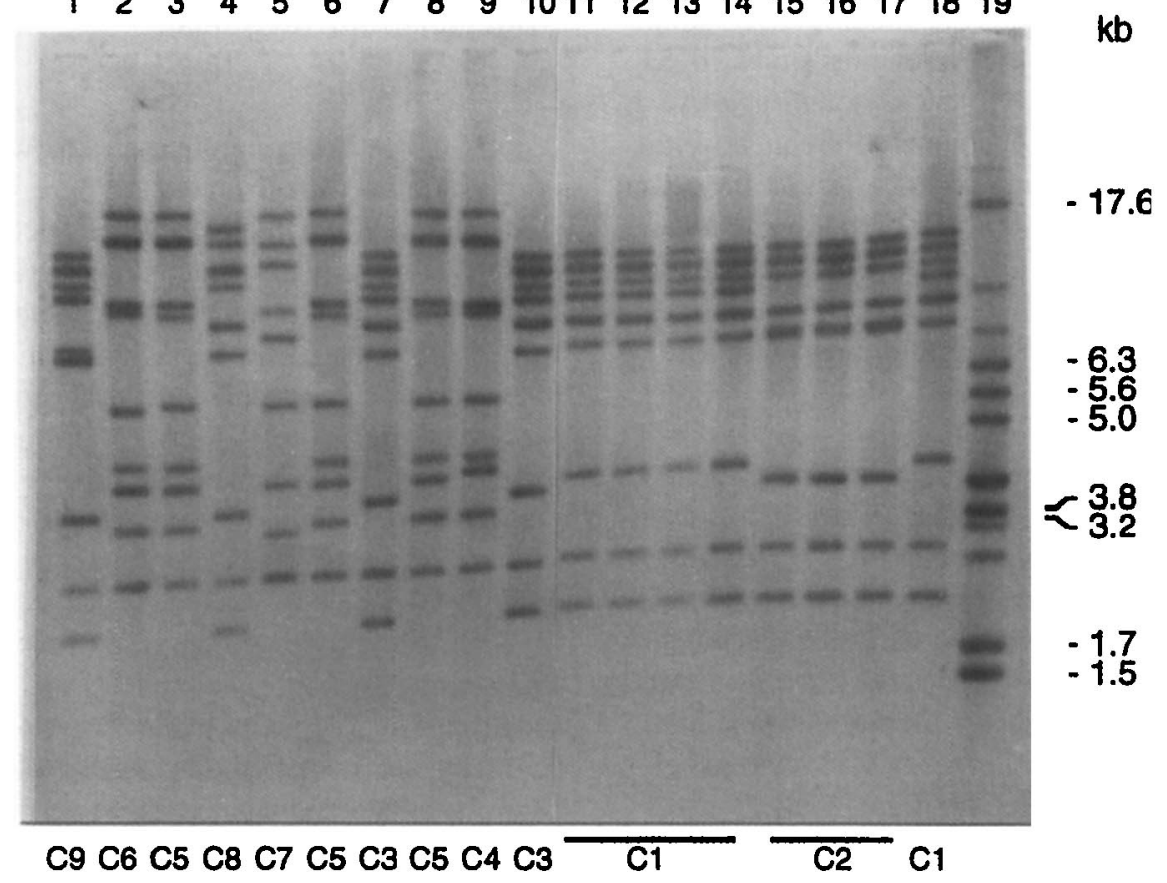

Fig. 1. ClaI restriction fragments of $18 P$. alcalifaciens strains hybridised with $E$. coli rRNA probe labelled with digoxigenin-11-dUTP. Lanes: 1-10, non-invasive strains (39133, 8894, 5271-0, 565, 6634, 4521-8, 4201-7, 0301-9, 2101-15, 0181-9, respectively); 11-18, invasive strains (681-8, 4002-10, 3761-8, 40448, 762-8, 9045-3, 2401-2, 47176, respectively); 19, H. aegyptius 3031 EcoRI digest. Fragment sizes (kb) are shown on the right. Letters at the bottom correspond to the ribotypes listed in Table 1. 


\section{$\begin{array}{lllllllllllllllllllll}\text { E8 } & \text { E9 } & \text { E5 } & \text { E4 } & \text { E3 } & \text { M7 } & \text { M4 } & \text { M6 } & \text { M5 } & \text { M3 } & \text { P } & \text { E2 } & \text { E1 } & \text { C2 } & \text { C1 } & \text { M2 } & \text { M1 } & \text { P } & \text { kb }\end{array}$}

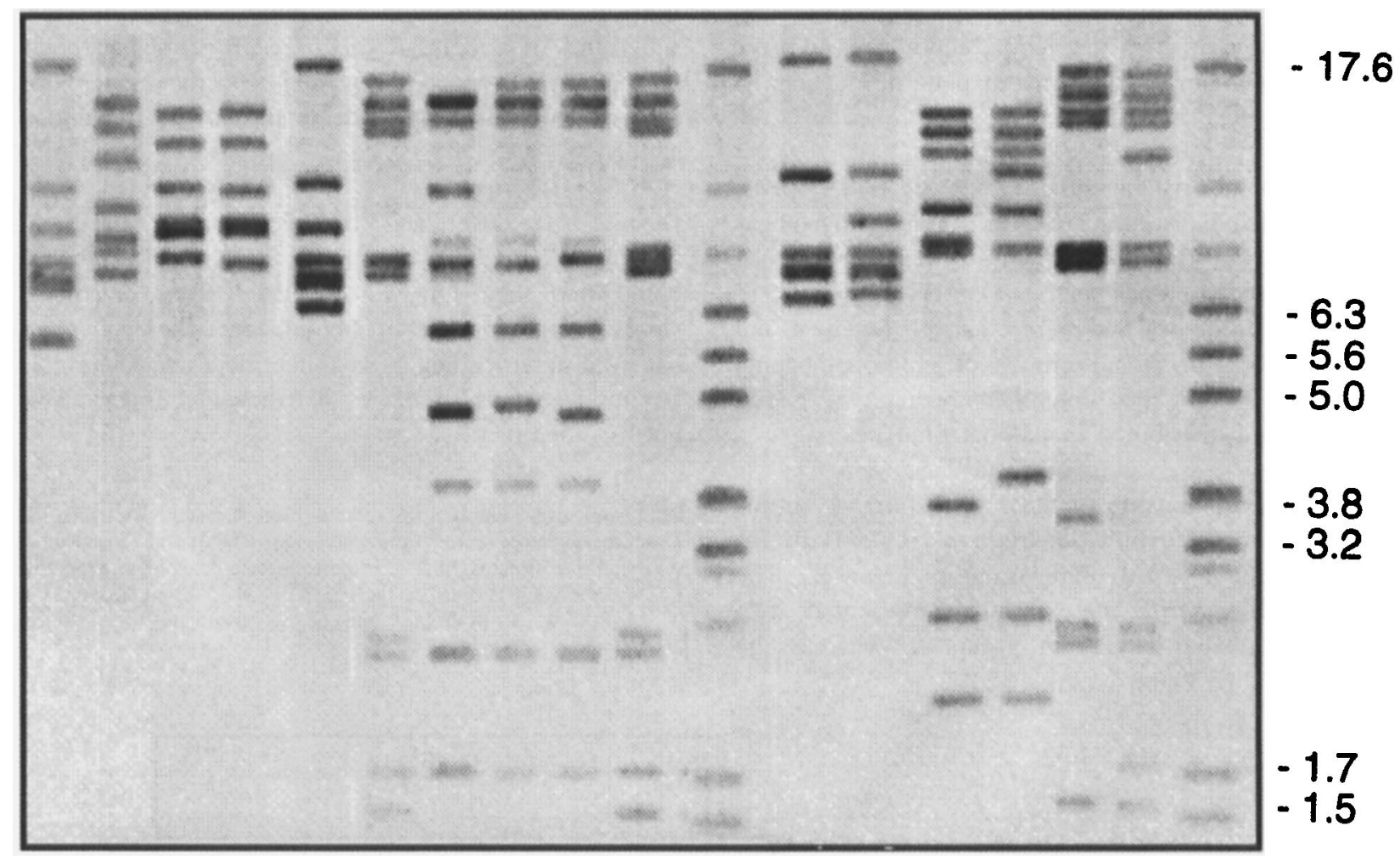

Fig. 2. Representative ribotype patterns of $P$. alcalifaciens strains obtained after digestion with EcoRV, MluI and Cla I. Panel A, ribotypes of non-invasive strains; panel B, ribotypes of invasive strains. Letters correspond to the different ribotypes listed in Table 1; P, H. aegyptius 3031 DNA digested with EcoRI. Fragment sizes (kb) are shown on the right.

Table 1. Ribotypes and characteristics of $P$. alcalifaciens strains isolated in São Paulo, Brazil

\begin{tabular}{|c|c|c|c|c|c|c|}
\hline \multirow{2}{*}{$\begin{array}{l}\text { Strain } \\
\text { No. }\end{array}$} & \multirow[b]{2}{*}{ Diarrhoea } & \multirow{2}{*}{$\begin{array}{l}\text { Year of } \\
\text { isolation }\end{array}$} & \multirow{2}{*}{$\begin{array}{l}\text { Invasive } \\
\text { phenotype }\end{array}$} & \multicolumn{3}{|c|}{ Ribotypes } \\
\hline & & & & Cla I & $E c o \mathrm{RV}$ & MluI \\
\hline 9938 & Yes & 1990 & + & $\mathrm{Cl}$ & E1 & M1 \\
\hline 47176 & Yes & 1990 & + & $\mathrm{Cl}$ & E1 & M1 \\
\hline 40448 & Yes & 1990 & + & $\mathrm{Cl}$ & E1 & M1 \\
\hline $3761-8$ & Yes & 1989 & + & $\mathrm{C} 1$ & E1 & M1 \\
\hline $4002-10$ & No & 1989 & + & $\mathrm{Cl}$ & $\mathrm{E} 1$ & M1 \\
\hline $681-8$ & Yes & 1989 & + & $\mathrm{Cl}$ & E1 & M1 \\
\hline $2401-2$ & Yes & 1989 & + & $\mathrm{C} 2$ & E2 & M2 \\
\hline $9045-3$ & Yes & 1988 & + & $\mathrm{C} 2$ & $\mathrm{E} 2$ & M2 \\
\hline $762-8$ & No & 1989 & + & $\mathrm{C} 2$ & E2 & $\mathrm{M} 2$ \\
\hline $0181-9$ & Yes & 1989 & - & $\mathrm{C} 3$ & E3 & M3 \\
\hline $2101-15$ & Yes & 1989 & - & $\mathrm{C} 4$ & E4 & M5 \\
\hline $0301-9$ & Yes & 1989 & - & C5 & E5 & M6 \\
\hline $4201-7$ & Yes & 1989 & - & C3 & E6 & M3 \\
\hline $4521-8$ & Yes & 1989 & - & C5 & E7 & M6 \\
\hline $5271-0$ & Yes & 1989 & - & C5 & E7 & M6 \\
\hline 6634 & Yes & 1990 & - & $\mathrm{C} 7$ & E8 & M7 \\
\hline 565 & Yes & 1986 & - & $\mathrm{C} 8$ & E9 & M4 \\
\hline 8894 & Yes & 1988 & - & C6 & E10 & M8 \\
\hline 39133 & Yes & 1990 & - & C9 & $\mathrm{E} 2$ & M4 \\
\hline
\end{tabular}

P. stuartii strains isolated from several hospitals in the UK and showed that the method distinguished between strains and also separated them from allied Providencia and Proteus spp.
In the present study, a combination of the ribotype patterns obtained with three selected enzymes produced 11 distinct ribotypes among $19 P$. alcalifaciens strains isolated from patients with diarrhoea in São 
Paulo City (Table 1). These strains could not be distinguished by biochemical tests, because all had the same biotype (data not shown). Moreover, it should be noted that the invasive $P$. alcalifaciens strains were found in only two of the 11 ribotype patterns (1 and 2) irrespective of the restriction endonuclease used, and most of them $(67 \%)$ were in pattern 1 (Table 1; Fig. 1).

Recently, Dalla-Costa et al. [17] showed that ribotyping was able to discriminate clones among diarrhoeagenic $E$. coli strains displaying different virulence markers. Related clones such as O55:H7 and 0157:H7 had similar ribotypes and were clustered together, and the two divergent clonal groups of enteropathogenic $E$. coli (EPEC) and enterohaemorrhagic E. coli (EHEC) were distributed in distinct branches.

The genetic relationship of the $P$. alcalifaciens strains studied is presented in a dendrogram (Fig. 3). Strains were clustered into two main groups (A and $\mathrm{B}$ ). The invasive $P$ alcalifaciens strains represented two genetically related clones in group $\mathrm{A}$, whereas the other strains not harbouring this virulence property comprised a more diverse group distributed either in clusters A or B. These results confirmed an earlier suggestion [4] that $P$. alcalifaciens strains isolated from diarrhoeal stools in São Paulo comprise different subgroups of strains. P. alcalifaciens strains harbouring invasive properties represent specific clones that seem to be distributed endemically in the population studied.

Despite the differences observed among the noninvasive $P$. alcalifaciens strains, it should be remembered that they too were isolated from diarrhoeal stools in pure culture or from faeces where no other bacterial enteropathogen was identified, and some may be implicated as agents of diarrhoea by mechanisms not yet identified.

This work was suported by grants from Conselho Nacional de Desenvolvimento Científico e Tecnológico (CNPq) and Financiadora de Estudos e Projetos/Ministério da Ciência e Tecnologia/Programa de Apoio a Núcleos 'de Excelência (FINEP/MCT/Pronex). We thank T. M. I. Vaz, J. Rodrigues and L. S. Nishimura for technical assistance.

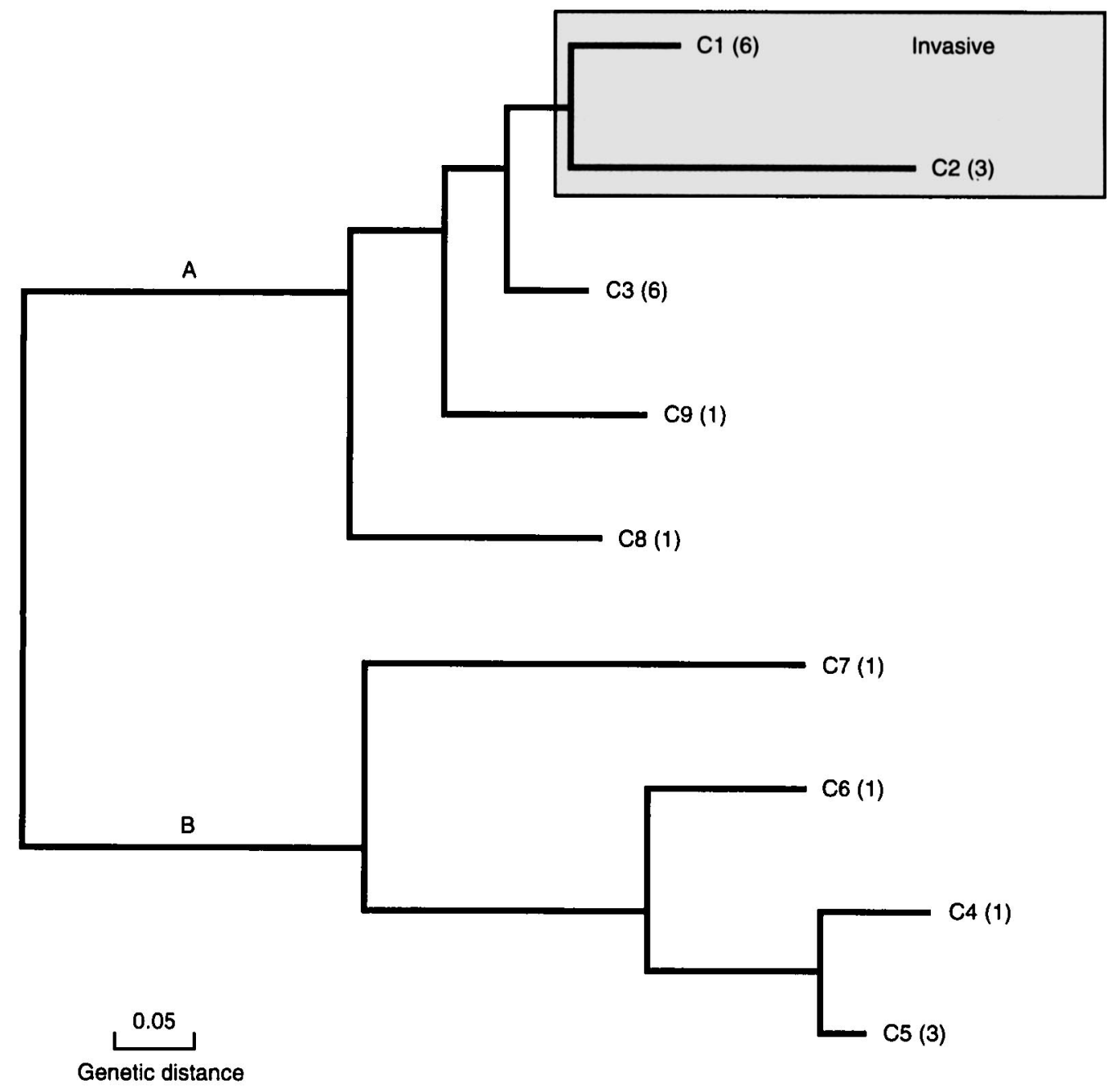

Fig. 3. Dendrogram showing the relationships among $P$. alcalifaciens strains isolated from diarrhoea in São Paulo City. The tree was constructed by applying UPGMA to a matrix of similarity established from the ribotype data obtained with Cla I cleavage. 


\section{References}

1. Haynes J, Hawkey PM. Providencia alcalifaciens and travellers' diarrhoea. $B M J$ 1989; 299: 94-95.

2. Albert MJ, Alam K, Ansaruzzaman M et al. Pathogenesis of Providencia alcalifaciens-induced diarrhea. Infect Immun 1992; 60: $5017-5024$.

3. Albert MJ, Ansaruzzaman M, Bhuiyan NA, Neogi PBK, Faruque ASG. Characteristics of invasion of HEp-2 cells by Providencia alcalifaciens. J Med Microbiol 1995; 42: $186-190$.

4. Guth BEC, Perrella E. Prevalence of invasion ability and other virulence-associated characteristics in Providencia alcalifaciens strains isolated in São Paulo, Brazil. J Med Microbiol 1996; 45: $459-462$.

5. Grimont F, Grimont PAD. Ribosomal ribonucleic acid gene restriction patterns as potential taxonomic tools. Ann Inst Pasteur/Microbiol 1986; 137B: 165-175.

6. Popovic T, Bopp CA, Olsvik O, Kiehlbauch JA. Ribotyping in molecular epidemiology. In: Persing DH, Tenover FC, Smith $\mathrm{TC}$, White TJ (eds) Diagnostic molecular microbiology. Washington, DC, American Society for Microbiology. 1993: 573-583.

7. Bingen EH, Denamur E, Elion J. Use of ribotyping in epidemiological surveillance of nosocomial outbreaks. Clin Microbiol Rev 1994; 7: 311-327.

8. Stull TL, LiPuma JJ, Edlind TD. A broad-spectrum probe for molecular epidemiology of bacteria: ribosomal RNA. $J$ Infect Dis 1988; 157: 280-286.

9. Brenner DJ, McWhorter AC, Knutson JKL, Steigerwalt AG. Escherichia vulneris: a new species of Enterobacteriaceae associated with human wounds. $J$ Clin Microbiol 1982; 15: $1133-1140$.

10. Southern EM. Detection of specific sequences among DNA fragments separated by gel electrophoresis. J Mol Biol 1975; 98: $503-517$.

11. Irino K, Grimont F, Casin I, Grimont PAD and the Brazilian Purpuric Fever Study Group. rRNA gene restriction patterns of Haemophilus influenzae biogroup aegyptius strains associated with Brazilian purpuric fever. J Clin Microbiol 1988; 26: $1535-1538$.

12. Kumar S, Tamura K, Nei M. MEGA: Molecular Evolutionary Genetics Analysis, version 1.0. The Pennsylvania State University, University Park, PA, USA. 16802.

13. Chetoui H, Delhalle E, Osterrieth P, Rousseaux D. Ribotyping for use in studying molecular epidemiology of Serratia marcescens: comparison with biotyping. J Clin Microbiol 1995; 33: 2637-2642.

14. Iteman I, Guiyole A, Carniel E. Comparison of three molecular methods for typing and subtyping pathogenic Yersinia enterocolitica strains. J Med Microbiol 1996; 45: 48-56.

15. Liebisch B, Schwarz S. Molecular typing of Salmonella enterica subsp. enterica serovar Enteritidis isolates. $J$ Med Microbiol 1996; 44: 52-59.

16. Owen RJ, Beck A, Dayal PA, Dawson C. Detection of genomic variation in Providencia stuartii clinical isolates by analysis of DNA restriction fragment length polymorphisms containing rRNA cistrons. $J$ Clin Microbiol 1988; 26: 2161-2166.

17. Dalla-Costa LM, Irino $\mathrm{K}$, Rodrigues J, Rivera ING, Trabulsi LR. Characterisation of diarrhoeagenic Escherichia coli clones by ribotyping and ERIC-PCR. J Med Microbiol 1998; 47: $227-234$ 